\title{
Environment at the time of injury determines injury patterns in pelvic blast
}

\author{
Claire Elizabeth Webster, ${ }^{1}$ J Clasper, ${ }^{2}$ I Gibb, ${ }^{3}$ S D Masouros ${ }^{4}$
}

${ }^{1}$ Centre for Blast Injury Studies, Imperial College London, London, UK

${ }^{2}$ Academic Department of Military Surgery and Trauma, Royal Centre for Defence Medicine, Birmingham, UK ${ }^{3}$ Radiology, HMS Nelson, Portsmouth, UK

${ }^{4}$ The Royal British Legion Centre for Blast Injury Studies, Imperial College London, London, UK

\section{Correspondence to}

Claire Elizabeth Webster, Centre for Blast Injury Studies, Imperial College London, London SW7 2AZ, UK; claire_elizabeth999@ hotmail.com

Received 1 May 2018 Revised 12 June 2018 Accepted 13 June 2018

Published Online First

22 December 2018

Check for updates

(C) Author(s) (or their employer(s)) 2019. No commercial re-use. See rights and permissions. Published by BMJ.

To cite: Webster CE,

Clasper J, Gibb I, et al.

I R Army Med Corps

2019:165:15-17.

\section{ABSTRACT}

The use of explosives by terrorists, or during armed conflict, remains a major global threat. Increasingly, these events occur in the civilian domain, and can potentially lead to injury and loss of life, on a very large scale. The environment at the time of detonation is known to result in different injury patterns in casualties exposed to blast, which is highly relevant to injury mitigation analyses. We describe differences in pelvic injury patterns in relation to different environments, from casualties that presented to the deployed UK military hospitals in Iraq and Afghanistan. A casualty on foot when injured typically sustains an unstable pelvic fracture pattern, which is commonly the cause of death. These casualties die from blood loss, meaning treatment in these should focus on early pelvic haemorrhage control. In contrast, casualties injured in vehicle present a different pattern, possibly caused by direct loading via the seat, which does not result in pelvic instability. Fatalities in this cohort are from injuries to other body regions, in particular the head and the torso and who may require urgent neurosurgery or thoracotomy as life-saving interventions. A different strategy is therefore required for mounted and dismounted casualties in order to increase survivors.

\section{INTRODUCTION}

Explosive incidents continue to be an enduring threat both abroad, and closer to home, with affected casualties sustaining a high injury burden and often fatal wounding patterns. ${ }^{1}$ They are no longer confined to the military environment, and the resulting injury patterns can be complex, and diverse. Knowledge of how blast affects the human is important for prevention, appropriate life-saving interventions, diagnostics and subsequent definitive treatment.

It has been recognised that the environment in which injury is sustained affects the pattern of wounding in both civilian and military casualties. ${ }^{2-4}$ Blast effects to buildings and people can be affected by characteristics of the explosive, surrounding infrastructure and the area in which it detonates. Military personnel have been shown to sustain different injury patterns if wounded on foot, and wounded in vehicle. ${ }^{5}$ Within vehicles, the majority of fatalities can be attributed to head injury, ${ }^{6}$ and to a slightly lesser extent, torso trauma. ${ }^{7}$ Out of vehicle, casualties sustain lower extremity wounding with injuries leading to exsanguination. ${ }^{68}$ This type of information allows more focused preventive strategies in both those casualties operating in vehicles, and on foot.

Lower extremity wounding occurred frequently in the conflicts in Iraq and Afghanistan. As the use of improvised explosive devices (IED) became

\section{Key messages}

The use and effects of improvised explosive devices continue to be a major global problem, and developing ways in which to reduce the human cost are vital.

- Blast injuries are diverse, and complex, leading to multisystem injuries. The majority of fatalities occur either at the time of injury, or shortly after. This means that prevention or mitigation of injury is key.

- Detailed knowledge of the effects of blast to human tissue is important to developing these preventive strategies. It is known that different environments produce different injury patterns; however, detailed knowledge of the differences with regard to pelvic injuries has not yet been reported.

- The data in this paper identify key differences in pelvic fracture patterns depending on the blast environment. In vehicle, casualties sustain rami, sacral and spinal fractures consistent with crush injury at the seat, with low levels of fatality due to the pelvic injury. Those on foot present with unstable pelvic fracture patterns, which is commonly the cause of fatality.

- This research identifies a focus for fatality prevention, in the dismounted casualty, which leads to unstable, and often fatal pelvic fractures. Further investigation of this injury mechanism could lead to development of more tailored injury mitigation techniques.

more widespread throughout the conflicts, proximal lower extremity injuries were seen as a characteristic feature of lower limb blast. ${ }^{9-11}$ This comprised traumatic lower limb amputation, and often more proximal pelvic and perineal injury, ${ }^{12}$ in which fatality was high. ${ }^{13}$ Although previous studies on military cohorts have linked the environment to particular wounding patterns in calcaneal fractures ${ }^{14}$ and the spine, ${ }^{5}$ no studies exist on pelvic trauma and the influence of the surroundings on its pattern. A strong investment in applied personnel protective equipment during the recent conflicts anecdotally reduced fatalities; however, casualties still died from this complicated wounding pattern. ${ }^{15}$ An understanding of the complexities of this wounding pattern will help clinicians with diagnostic and treatment processes in severe pelvic trauma. As well as improvements in treatment pathways, further focus is required prior to injury, in 
order to develop a cohesive, evidence-based preventive strategy that could reduce injury burden and improve survivability.

The aim of this study is to identify pelvic injury patterns in blast, determine which associated injuries contribute to fatality and relate this to the environment of the patient at the time of injury.

\section{METHODS}

The Joint Theatre Trauma Registry (JTTR) is a prospectively collected database of trauma casualties treated in UK military treatment facilities on operations. ${ }^{16}$ The database was analysed to identify casualties that sustained pelvic disruption due to blast injury during the conflicts in Iraq and Afghanistan, which spanned from 2003 to 2014.

The pelvic injury patterns of this cohort were identified by the author, using plain films, CT scans and three-dimensional reconstructions. The presence of pubic symphysis widening, pubic rami fracture, acetabular fracture, iliac blade fracture, sacroiliac joint disruption or sacral body fracture was noted. In addition, the presence of a spinal fracture, or associated traumatic amputation of the lower limb was recorded. For all casualties, the main body region injured was determined, defined as the highest abbreviated injury scale recorded within a body region.

Incident data, specifically whether casualties were mounted in vehicle or dismounted on foot, were obtained. Special permission was granted to gain access to this incident data using the information held at the Defence Science and Technology Laboratories, and expertise of engineers within this organisation was used.

Statistical analysis was performed using $\chi^{2}$, with significance set as 0.05 . The null hypothesis was that there is no difference in injury patterns in relation to position or environment at the time of injury.

\section{RESULTS}

Between 2003 and 2014, a total of 365 casualties sustained pelvic trauma from blast. Of these, $23(6.3 \%)$ casualties had insufficient radiological data available and were therefore excluded. This left 342 casualties who sustained a pelvic facture treated at a UK military facility, with full radiological and follow-up data available. There were 259 (76\%) military and 83 (24\%) civilian casualties; $99 \%$ were male, and the age range was 18-51 (median $=29$ ).

Of the 342 casualties, there were 177 survivors and 165 fatalities (48\% fatality rate). Up to 199 (58\%) of personnel were dismounted (on foot) at the time of injury, with $126(37 \%)$ mounted (in vehicle), and in 17 (5\%) the environment in which the injury was sustained was unrecorded. Although there was no difference in the fatality rates $(50 \%$ vs $50.7 \%, \mathrm{p}=0.911)$ between mounted and dismounted casualties, there was a higher casualties (medians of 50 and 15, respectively, compared with 35 and 11 , respectively, in dismounted casualties). The most severe injuries, and probable cause of death in mounted casualties, were injuries to the head and chest. In dismounted casualties, injuries to the lower extremities dominated. Therefore, within this data set, mounted casualties more often died of their associated injuries (72\%), rather than pelvic injury, and dismounted casualties died predominantly of their lower extremity injury $(80 \%)$ $(p=0.0001)$ (Table 1). Head injury was the most prolific injury in terms of mortality; however, in terms of frequency, lower extremity injury was responsible for the most fatalities in this cohort (Table 1).

Specific locations of pelvic injury were identified from the radiological data, and striking differences were noted between Injury Severity Score and total number of injuries in mounted

Table 1 Main body regions injured, fatality and environment at the time of injury

\begin{tabular}{|c|c|c|c|c|}
\hline & \multicolumn{2}{|c|}{ Dismounted $(n=199)$} & \multicolumn{2}{|c|}{ Mounted ( $n=126)$} \\
\hline & Incidence (\%) & $\begin{array}{l}\text { Fatality } \\
\text { rate, } \%\end{array}$ & Incidence (\%) & $\begin{array}{l}\text { Fatality } \\
\text { rate, } \%\end{array}$ \\
\hline Lower extremity & $164(82)$ & 44 & $39(31)$ & 25 \\
\hline $\begin{array}{l}\text { Head (including face, } \\
\text { neck) }\end{array}$ & $19(10)$ & 79 & $47(37)$ & 81 \\
\hline Thorax & $10(5)$ & 100 & $26(21)$ & 22 \\
\hline Abdomen & $6(3)$ & 75 & $12(9.5)$ & 30 \\
\hline Upper extremity & $0(0)$ & 0 & $2(1.5)$ & 0 \\
\hline
\end{tabular}

those in vehicle and on foot when injured. Table 2 demonstrates a direct comparison of these pelvic injury patterns and directly associated injuries between mounted and dismounted casualties.

\section{DISCUSSION}

This study adds further evidence to the literature that there are distinct differences in injury patterns between casualties injured while in vehicle and on foot. Mounted casualties have a higher overall injury burden, with fatalities predominantly due to injuries to the head or thorax. Those injured on foot generally have injuries isolated to the lower extremity, with fewer injuries to other body regions, and fatalities are secondary to severe disruption at the lower extremity, including the pelvis.

This is also the first analysis to provide a distinction between the types of pelvic injury seen, depending on the environment of the casualty at the point of injury. Those casualties in vehicle sustain a wider spread of injury pattern compared with dismounted, with predominantly pubic rami and spinal fractures being the most frequent patterns seen, which are not associated with fatality. Fatalities in this group were a result of associated injuries to the head and torso. Dismounted victims sustain predominantly disruption at the sacroiliac joints and pubic symphysis, and have a high incidence of traumatic amputation. These casualties die predominantly from their lower extremity and pelvic injury, and not from associated injuries to other body areas.

The results of this study suggest that the strategy for immediate clinical interventions and for protection for those in vehicle and on foot needs to be different. Those dismounted require a focus on control of lower extremity and pelvic haemorrhage. Prevention of the resulting exsanguination should focus on reducing the risk of an unstable pelvic fracture. Conversely, mounted casualties require a focus on protection of their head and chest.

There therefore appears to be a different process occurring leading to injury patterns in those mounted compared with dismounted. The seated pelvis exposed to underbody blast that occurs in vehicle is likely to have a direct impact on the pelvis,

Table 2 Injury patterns and environment at the time of injury (values in bold indicate stastistical significance)

\begin{tabular}{llll}
\hline Pelvic injury & $\begin{array}{l}\text { Mounted } \\
(\mathbf{n}=126)\end{array}$ & $\begin{array}{l}\text { Dismounted } \\
(\mathbf{n}=199)\end{array}$ & P values \\
\hline Pubic symphysis disruption & $42(33 \%)$ & $137(69 \%)$ & 0.0001 \\
Sacroiliac joint disruption & $42(33 \%)$ & $143(72 \%)$ & 0.0001 \\
Pubic ramus fracture & $66(52 \%)$ & $72(36 \%)$ & 0.0056 \\
Sacral fracture & $40(32 \%)$ & $68(43 \%)$ & 0.7173 \\
Spinal fracture & $58(46 \%)$ & $40(20 \%)$ & 0.0001 \\
Acetabular fracture & $40(32 \%)$ & $58(29 \%)$ & 0.6221 \\
\hline Traumatic amputation & $33(26 \%)$ & $152(76 \%)$ & 0.0001 \\
\hline
\end{tabular}


causing fractures to structures in contact-the pubic rami and sacrum-with relative sparing of the sacroiliac joints and pubic symphysis. There is a low incidence of traumatic amputation occurring in vehicle. These casualties are also more likely to sustain a spinal injury, suggesting that forces are being transmitted cranially. Anecdotally, these injuries are rarely contaminated with secondary blast fragments such as sand and grit, as the surrounding vehicle provides protection. There have been some efforts to replicate experimentally mounted injury patterns; however, they have not been based on robust clinical data sets, and do not necessarily represent realistic clinical end points ${ }^{17}$.

In contrast, dismounted casualties sustain fewer rami and sacral fractures. They sustain widening at the pubic symphysis and sacroiliac joints and also relative sparing of the spine, suggesting a different mechanism of injury and/or force direction to that in the mounted casualties. The dismounted casualties commonly sustain a traumatic amputation, and have significant contamination from high-velocity fragments, soil and grit. As the pelvic injuries of the dismounted casualty are more likely to be fatal, an understanding of how pelvis injury was caused is important. We propose three possible mechanisms for this. Axial load via the femoral head could cause load propagation to the acetabulum, but instead of acetabular fracture, the femoral head displaces the hemipelvis causing superior lateral separation. This mechanism is likely to require direct impact from standing on an IED. Flail of the lower limb has been hypothesised as a mechanism of traumatic amputation, ${ }^{8}$ and has the potential to also displace the hemipelvis laterally causing disruption at the pubic symphysis and sacroiliac joints. Third, blast wind and fragmentation may be severe enough to displace the pelvis in a 'sand blast' type effect. This potential for high-velocity fragments to cause tissue injury, by displacement rather than direct damage has not yet been studied.

Although appropriate responses in mass casualty situations such as blast are important for rapid casualty evacuation and initiation of life-saving treatment, ${ }^{18}$ prevention of injury is key for advancing survivors of blast injury. Physiologically, there are potentially opportunities to intervene, and options are being considered such as predeployment physical conditioning, preoperative tranexamic acid to reduce bleeding if injured, early administration of antibiotics, remote physiological monitoring or prophylactic psychological consultation. Alterations to protective equipment, and alterations to the design of vehicles are also within the sphere of damage-limiting interventions, and optimising this is key to lessening both morbidity and mortality from combat wounds, and helping to reduce the brutal nature of war injuries for those who are most at risk. With regard to pelvic disruption, findings in this study indicate that prevention of pelvic injuries in vehicle is likely to be of little benefit to survival, as these casualties mostly died of their associated injuries. Improving survival in mounted casualties needs to be focused on prevention of injury to the head and thorax. Dismounted casualties, however, do die from their pelvic injury, therefore, preventing in pelvic fracture should be the focus in increasing survivability of the dismounted.

Although casualties were identified retrospectively, this was using a prospectively collected database, which included all the injury data that we required. Subsequent analysis of the imaging was carried out specifically for this study, and the fact that only $6.3 \%$ of casualties had insufficient data confirms the quality of data collection. Although not impossible because of the nature of the JTTR database and collection, it is highly unlikely that any casualty who had a significant pelvic injury was not included on the database, as even late diagnoses would be entered.

\section{CONCLUSION}

This study identified that although the death rates were almost identical in those casualties in vehicle and on foot, the cause of death and injury patterns were substantially different. Casualties in vehicle died of head or chest injury and their pelvic fractures were mostly stable. Casualties on foot had mostly unstable pelvic fractures combined with traumatic amputations and these injuries were resulting in death due to exsanguination. Observations in this study suggest that protection in vehicle should focus on head and chest injury, and focuses the survival improvement strategy in pelvic trauma on the dismounted soldier on preventing pelvic opening.

Acknowledgements Thanks are given to the Royal British Legion whose continued support to the Centre for Blast Injury Studies is invaluable. Thanks also to the Royal Centre for Defence Medicine Radiology Department and the Defence Science and Technology Laboratories.

Contributors All authors had key contributions to data collection, analysis and writing of the manuscript.

Funding The authors would like to thank the Royal British Legion for their ongoing financial support for research activity at the Centre for Blast Injury studies.

Competing interests None declared.

Patient consent Not required.

Provenance and peer review Not commissioned; internally peer reviewed.

\section{REFERENCES}

1 Edwards DS, McMenemy L, Stapley SA, et al. 40 years of terrorist bombings - A metaanalysis of the casualty and injury profile. Injury 2016;47(3):646-52.

2 Hepper AE, Pope DJ, Bishop M, et al. Modelling the blast environment and relating this to clinical injury: experience from the $7 / 7$ inquest. J R Army Med Corps 2014;160:171-4

3 Covey DC, Ficke JR. Blast and Fragment Injuries of the Musculoskeletal System," in Orthopedics in Disasters, Berlin, Heidelberg: Springer Berlin Heidelberg, 2016:269-80.

4 Edwards DS, Clasper J. "Blast Injury Mechanism, " in Blast Injury Science and Engineering, Cham: Springer International Publishing, 2016:87-104.

5 Singleton JA, Gibb IE, Hunt NC, et al. Identifying future 'unexpected' survivors: a retrospective cohort study of fatal injury patterns in victims of improvised explosive devices. BMJ Open 2013;3:e003130.

6 Mac Donald CL, Johnson AM, Cooper D, et al. Detection of blast-related traumatic brain injury in U.S. military personnel. N Eng/ J Med 2011;364:2091-100.

7 Ramasamy A, Harrisson SE, Clasper JC, et al. Injuries from roadside improvised explosive devices. J Trauma 2008;65:910-4.

8 Singleton JAG, Gibb IE, Bull AMJ, et al. Traumatic amputation from explosive blast: evidence for a new injury mechanism Bone Jt. J Orthop Proc Supp/ 2013;95:2.

9 Ramasamy A, Evans S, Kendrew JM, et al. The open blast pelvis. J Bone Joint Surg Br 2012;94-B:829-35

10 Poon H, Morrison JJ, Clasper JC, et al. Use and complications of operative control of arterial inflow in combat casualties with traumatic lower-extremity amputations caused by improvised explosive devices. J Trauma Acute Care Surg 2013;75:S233-S237.

11 Webster CE, Clasper J, Stinner DJ, et al. Characterization of lower extremity blast injury. Mil Med 2018.

12 Jacobs N, Rourke K, Rutherford J, et al. Lower limb injuries caused by improvised explosive devices: proposed 'Bastion classification' and prospective validation. Injury 2014:45:1422-8

13 Webster C, Masouros S, Gibb I, et al. Fracture patterns in pelvic blast injury: a retrospective analysis and implications for future preventative strategies. Orthop Proc 2015:97(SUPP 8).

14 Ramasamy A, Hill AM, Phillip R, et al. The modern "deck-slap" injury-calcaneal blast fractures from vehicle explosions. J Trauma 2011;71:1694-8.

15 Oh JS, Do NV, Clouser M, et al. Effectiveness of the combat pelvic protection system in the prevention of genital and urinary tract injuries: An observational study. J Trauma Acute Care Surg 2015;79:S193-S196.

16 Smith J, Hodgetts T, Mahoney P, et al. Trauma governance in the UK defence medical services. J R Army Med Corps 2007;153:239-42.

17 Bailey AM, Christopher JJ, Brozoski F, et al. Post mortem human surrogate injury response of the pelvis and lower extremities to simulated underbody blast. Ann Biomed Eng 2015;43:1907-17.

18 Lerner EB, Schwartz RB, McGovern JE. Prehospital triage for mass casualties, " in Emergency Medica/ Services. Chichester, UK: John Wiley \& Sons, Ltd, 2015:288-91. 